\title{
How infections can modify lung immunity
}

\author{
L.P. Nicod*, M.A. Spiteri ${ }^{\#}$
}

Several studies have reported low rates of allergic sensitization and allergies in children exposed to respiratory tract infections $[1,2]$ or a rural environment [3]. The role of immunity in controlling infections has been well explored in the past, but the longlasting effect of infections on immunity in health and disease is still largely unknown. It is, therefore, important to consider current knowledge on lung defences in order to find new approaches in identifying how infections may modulate T-helper (Th)1/Th2 immunity.

There has been increasing evidence in previous literature linking host innate immunity, triggered by many infectious agents, and acquired immunity with its specific humoral and cellular responses. Innate immunity is driven through the actions of a variety of cell types, including macrophages, eosinophils, basophils and T-lymphocytes, such as $\gamma \delta$ T-cells or natural killer (NK) cells. Innate immunity can be triggered by: lipopolysaccharides via receptors, such as CD14, in conjunction with the Toll 4 receptors; bacterial peptidoglycans interacting with Toll 2 receptors; bacterial deoxyribonucleic acid (DNA) and Toll 9 receptors [4]. Mast cells, eosinophils and T-cells can be activated by their own specific receptors. All these cells can release a wide array of biologically active mediators capable of controlling invading pathogens, together with chemokines, which selectively attract mono- and polymorphonuclear cells. In addition, they can also release "danger signals", such as interleukin (IL)-1 and tumour necrosis factor (TNF)- $\alpha$, which can activate dendritic cells located around the airways and blood vessels. Dendritic cells are critical in local surveillance of invading organisms and inhaled particles [5]. They can phagocytose neighbouring epithelial cells invaded by viruses [6] and migrate to draining lymph nodes in the lungs, whereupon antigen presentation, specific cellular and humoral immune responses are initiated; hence the term acquired immunity. Dendritic cells act in a similar manner with other intracellular bacteria or intruding organic particles. Activated dendritic cells take 6-24 h to travel to nearby lymph nodes, and 3-4 days to trigger and drive T-cells to replicate. After several replication

*Dept of Internal Medicine, Division of Pulmonary Medicine, University Hospital of Geneva, Switzerland. ${ }^{\#}$ Dept of Respiratory Medicine, North Staffordshire Hospital, Stoke-on-Trent, UK.

Correspondence: L.P. Nicod, Dept of Internal Medicine, Division of Pulmonary Medicine, University Hospital of Geneva, 24, rue Micheli-du-Crest, 1211 Geneva 14, Switzerland. Fax: 4122729929. cycles, T-cells (and probably B-cells) will migrate to peripheral lymphoid organs and tissues in the form of memory cells $[7,8]$.

To date, there remain crucial questions that have yet to be resolved: the type of Th1 or Th2 responses initiated by specific molecules of invading pathogens $[9,10]$; the impact of the tissular inflammatory milieu in conditioning the diversion of $\mathrm{Th} 0$ into either $\mathrm{Th} 1$ or Th2 responses; the role played by the genetic background of the host in favouring a Th1 or Th2 response, which appear critical in the development of diseases, such as asthma, or in host immunity against pathogens, such as tuberculosis. Indeed, defects in the production of either interferon (IFN)- $\gamma$ or its receptor, as well as in IL-12 production, have been shown to favour severe forms of tuberculosis in human [11].

The "Lung infections and immunity" Series will address some of these questions and highlight recent developments in the understanding of diverse and intricate interactions involved between infections and host innate and acquired immune mechanisms. C. Pilette, from the group of Y. Sybille, will review the mucosal defences, specifically the role of secretory immunoglobulin-A (IgA) within the airway epithelial barrier. B. Lambrecht will discuss newly discovered aspects of the complex immune regulatory system within the lung, in which dendritic cells play a pivotal role in bridging innate and acquired immunity. B.B. Moore et al. will describe the critical function of T-cells, NK cells and CD4 and CD8 cells in building an efficient acquired immunity, and how B-cells generate a complete humoral response. In particular, they highlight interacting pathways between innate host defence and specific immune reactions in counteracting infective insults to the lung. S. Message and S. Johnston will cover the mechanisms via which various respiratory viruses may influence the development of asthma, and outline the consequences of preexisting lung disease on viral clearance. R. Crameri will focus on the role of host control mechanisms of fungal colonization in preventing development of invasive, systemic infection, demonstrating how fungi can replicate some of the host's own molecular structures, leading to onset of allergic/autoimmune reactions. V. DeRose will summarize the clinical difficulties encountered in infective exacerbations associated with cystic fibrosis, with particular focus on how these infections interfere with the local defences in these patients. Lastly, P. Holt will review epidemiological and fundamental studies that associate perinatal and 
early childhood infections with host predisposition to asthma, and describe the influence of host genetic profile and atopy.

Overall, the reader should find that the Series provides an important source of references and offers some insight into how pathogens can escape various defences. The Series will also provide examples of the importance of structure and enzymatic content of pathogens, which leads to various inflammatory patterns. Assuming the predominance of memory CD4 or CD8 T-cells in nonlymphoid tissues has recently been clearly shown $[7,8]$, their role in the required balance between $\mathrm{T}$-helper 1 and $\mathrm{T}$-helper 2 responses when exposed to foreign particles is obviously still a matter of speculation.

\section{References}

1. Ball TM, Castro-Rodriguez JA, Griffith KA, Holberg CJ, Martinez FD, Wright AL. Siblings, day-care attendance, and the risk of asthma and wheezing during childhood. $N$ Engl J Med 2000; 343: 538-543.

2. Illi S, von Mutius E, Lau S, et al. Early childhood infectious diseases and the development of asthma up to school age: a birth cohort study. BMJ 2001; 322: 390-395.

3. Braun-Fahrlander C. Allergic diseases in farmers' children. Pediatr Allergy Immunol 2000; 11: Suppl. 13, 19-22.
4. Krutzik SR, Sieling PA, Modlin RL. The role of Tolllike receptors in host defense against microbial infection. Curr Opin Immunol 2001; 13: 104-108.

5. Nicod LP, Cochand L, Dreher D. Antigen presentation in the lung: dendritic cells and macrophages. Sarcoidosis Vasc Diffuse Lung Dis 2000; 17: 246255.

6. Albert ML, Sauter B, Bhardwaj N. Dendritic cells acquire antigen from apoptotic cells and induce class 1-restricted CTLs. Nature 1998; 392: 86-89.

7. Vermaelen KY, Carro-Muino I, Lambrecht BN, Pauwels RA. Specific migratory dendritic cells rapidly transport antigen from the airways to the thoracic lymph nodes. J Exp Med 2001; 193: 51-60.

8. Masopust D, Vezys V, Marzo AL, Lefrancois L. Preferential localization of effector memory cells in nonlymphoid tissue. Science 2001; 291: 2413-2416.

9. Thoma-Usynski S, Kiertscher SM, Ochoa MT, et al. Activation of toll-like receptor 2 on human dendritic cells triggers induction of IL-12, but not IL-10. J Immunol 2000; 165: 3804-3810.

10. Dreher D, Kok M, Cochand L, et al. Genetic background of attenuated Salmonella typhimurium has profound influence of infection and cytokine patterns in human dendritic cells. J Leukoc Biol 2001; 69: 1-8.

11. Dupuis S, Doffinger R, Picard C, et al. Human interferon-gamma-mediated immunity is a genetically controlled continuous trait that determines the outcome of mycobacterial invasion. Immunol Rev 2000; 173: 129-137. 